\title{
PENGARUH MODEL PEMBELAJARAN INQUIRY TRAINNING TERHADAP HASIL BELAJAR SISWA PADA MATERI POKOK BESARAN DANSATUAN DI KELAS $X$ SEMESTER ISMA NEGERI 7 MEDAN
}

\author{
Tjiufen Viin M Manurung *) dan Nurdin Siregar **) \\ *) Mahasiswa Jurusan Fisika FMIPA UNIMED \\ **) Dosen Jurusan Fisika FMIPA UNIMED
}

\section{Mentari_cute92@yahoo.com}

\begin{abstract}
ABSTRAK
Penelitian ini bertujuan untuk mengetahui pengaruh model pembelajaran Inquiry Training terhadap hasil belajar fisika siswa SMA dan aktivitas belajar siswa selama proses pembelejaran. Penelitian ini menggunakan metode quasi eksperimen dengan desai penelitian Two Group Pretest-Postest Design. Populasi dalam penelitian ini adalah seluruh siswa kelas X SMA N 7 Medan yang terdiri dari 5 kelas dan sampel 2 kelas yang ditentukan secara cluster rondom sampling, yaitu kelas X IPA 5 sebagai kelas eksperimen dan kelas X IPA 1 sebagai kelas kontrol. Dari uji hipotesis diperoleh ada pengaruh yang signifikan antara hasil belajar siswa dengan pembelajaran inquiry training dan pemebelajaran konvensional pada materi pokok besaran dan satuan dikelas X SMA N 7 Medan.
\end{abstract}

Kata Kunci : Model pembelajaran inquiry training.

\section{PENDAHULUAN}

Pendidikan sebagai salah satu sektor paling penting dalam pembangunan nasional, dijadikan sebagai andalan utama untuk berfungsi semaksimal mungkin dalam upaya meningkatkan kualitas hidup manusia Indonesia. Di samping perkembangan ilmu pengetahuan, perkembangan teknologi yang pesat juga menuntut kita untuk mampu bersaing dan sejajar dengan bangsa-bangsa lain dalam perkembangn tersebut. Yang menjadi masalah adalah lemahnya proses pembelajaran sebagai proses interaksi guru dengan siswa dalam mempelajari materi yang telah tersusun dalam suatu kurikulum. Permasalahan yang sering ditemukan adalah minat dan keaktifan siswa dalam belajar. Hal ini dapat dilihat dari hasil belajar siswa yang diperoleh setelah akhir pelajaran, ulangan harian dan ujian semester yang masih rendah.

Peneliti mewawamcarai guru mata pelajaran fisika di SMAN 7 Medan. Beliau mengatakan hasil belajar siswa cenderung masih rendah yaitu rata-rata 62,40 padahal Kriteria Ketuntasan Minimum yaitu 64,00. Data angket yang diperoleh menunjukkan bahwa 59,5\% siswa tidak menyukai pembelajaran Fisika di kelas karena sulit dipahami, kurang menarik, dan nmembosankan, 25, 53\% menyatakan bahwea pembelajaran fisika dikelas biasa saja, dan 14,89\% menyatakan bahwa pembelajaran Fisika di Kelas mudah dan menyenangkan. Berdasarkan angket juga diperoleh sebanyak $48,94 \%$ siswa menginginkan hasil 
belajar fisika sambil bermain, $29,79 \%$ siswa menginginkan belajar fisika dengan eksperimen dan demonstrasi, dan $21,27 \%$ menginginkan belajar dengan mengerjakan soal. Agar proses pembelajaran dapat berlangsung dengan baik, seorang guru harus bisa menciptakan susasana yang dapat menarik perhatian siswa dan melibatkan mereka dalam proses pembelajaran. Untuk itu guru harys dapat merencanakan, menyusun dan mendesain proses pembelajaran dengan menggunakan model, metode mengajar yang nantinya dapat memotivasi siswa dan meningkatkan hasil belajar siswa. Di samping itu guru diharapkan dapat merencanakan kegiatn yang berpengaruh pada siswa dalam hal pemahaman konsep materi pelajaran yang akhirnya dapat berdampak pada pencapaian hasil belajar yang optimal sehingga siswa tidak menganggap fisika itu sulit.

Model pembelajaran Inquiry Training adalah salah satu bentuk kegiatan yang di dapat mengaktifkan siswa dalam mengembangkan disiplin intelektual dan keterampilan siswa. Pada prinsipnya, model pembelajaran inquiry taining mewajibkan para siswa untuk mengajukan pertanyaan, namun siswa tidak sengaja meminta guru untuk menjawab pertanyaan tersebut, melainkan memnbuat hipotesis sendiri ( Joyce et all, 2009).

Pertanyaan tersebut dapat diajaukan sebagai bahan diskusi bersama teman sekelompoknya dan hipotesis tersebut akan mendapat hasil setelah diskusi kelompok dan eksperimen selesai. Pada akhirnya, penemuan pertanyaan serta jawaban sementara yang di buat sendiri dapat menyebabkan perubahan dan ketergantungan pada penguatan luar pada rasa puas akibat keberhasila nmenemukan sendiri,baik berupa pertanyaan atau masalah maupun atas jawaban permasalahan yang diajukan (Suryosubroto, 2009).

Berdasarkan hasil penelitian yang dilakukan oleh peneliti terdahulu yaitu Harahap F (2012) menerapkan model pembelajaran inquiry training pada materi pokok Suhu dan Kalor diperoleh nilai ratarata pretes di kelas eksperimen dan kelas kontrol adalah 35,5 dan 30,8. Setelah diberikan perlakuan pada kedua kelas diperoleh nilai rata-rata postes pada kelas eksperimen dan kelas kontrol adalah 78,7 dan 62,8. Aktivitas siswa selama melakukan pembelajaran inquiry training di kelas eksperimen dapat terlihat dari skor aktivitas siswa pada ketiga pertemuan yang mencapai 80,7 dengan predikat sangat aktif. Aktivitas siswa di kelas kontrol yang di ajar dengan cara belajar konvensional menunjukkan skor aktivitas 62,35 dengan predikat aktif. Namunpara peneliti masih memiliki kelemahan-kelemahan seperti : peneliti masih kurang dalam pengendalian kelas dikarenakan siswa kurang terbiasa dengan pembelajaran pendekatan inquiry training. Peneliti masihkurang mampu dalam menggunakan alokasi waktu sesuai dengan RPP. Peneliti susah membentuk kelompok dikarenakan siswa masih mengalami kebigungan sehingga suasana kelas menjadi kurang kondusif. Berdasarkan hal tersebut penulis akan berusaha lebih giat lagi mengkondusifkan kelas dan dalam pembelajaran di kelas penulis akan memfalisitasi siswa dengan bahan ajar. Di samping itu juga peneliti sebelumnya tidak melihat peningkatan aktivitas siswa di kelas 
eksperimen dan hal ini juga yang menjadi perbedaan dari penelitian sebelumnya. Tempat penelitian penulis kali ini akan dilaksanakan di SMA N 7 Medan karena sekolah tersebut mempunyai disiplin yang tinggi, siswanya heterogen seperti beda agama, suku dan juga daerah asal yang nantinya akan dipadukan pada saat diskusi pembelajaran.

\section{METODE PENELITIAN}

Penelitian ini termasuk quasi experiment. Penelitian ini dilaksanakan di SMA Negeri 7 Medan pada Semester I T.P. 2014 / 2015 .

Penelitian ini melibatkan dua kelas yang diberi perlakuan yang berbeda. Untuk mengetahui hasil belajar fisika siswa dilakukan dengan memberikan tes pada kedua kelas sebelum dan sesudah diberikan perlakuan. Desain penelitian dapat dilihat pada Tabel 1 .

Tabel.1 Two Group Pretest dan Postest

\begin{tabular}{|l|l|l|l|}
\hline Kelas & Pre Tes & Perlakuan & Pos Tes \\
\hline Eksperimen & $\mathrm{T}_{1}$ & $\mathrm{X}$ & $\mathrm{T}_{2}$ \\
\hline Kontrol & $\mathrm{T}_{1}$ & $\mathrm{Y}$ & $\mathrm{T}_{2}$ \\
\hline
\end{tabular}

Keterangan :

T1 : Tes kemampuan awal (pretes) untuk kelas eksperimen dan kelas kontrol.

T2 : Tes kemampuan akhir (postes) untuk kelas eksperimen dan kelas kontrol.

$\mathrm{X} 1$ : Perlakuan pembelajaran dengan model pembelajaran inquiry training.

Y : Perlakuan pembelajaran dengan model pembelajaran konvensional.
Hasil pretes yang diperoleh dilakukan uji prasyarat yaitu uji normalitas untuk mengetahui apakah data berdistribusi normal atau tidak. Kemudian dilakukan uji homogen untuk mengetahui apakah data bersifat homogen atau tidak. Setelah data berdistribusi normal dan juga homogen, maka dilakukan Uji t dua pihak (uji kemampuan awal/pretes) yang digunakan untuk mengetahui kesamaan kemampuan awal siswa pada kedua kelompok sampel. (Sudjana, 2005). Selanjutnya apabila kedua kelas sampel diketahui mempunyai kemampuan awal yang sama maka kedua sampel diberikan perlakuan yang berbeda. Kelas eksperimen diberikan perlakuan dengan model pembelajaran inquiry training dan kelas kontrol diberikan perlakuan dengan menggunaka model pembelajaran konvensional. Setelah diberikan perlakuan maka selanjutnya adalah kedua kelas diberikan postes. Untuk mengolah data pada postes sama seperti pada pretes dilakukan uji prasyarat yaitu uji normalitas dan uji homogen. Setelah data berdistribusi normal dan juga homogen maka dilakukaan uji $\mathrm{t}$ (uji kemampuan akhir/postes) yang digunakan untuk mengetahui apakah hasil belajar siswa dengan menerapkan model pembelajaran inquiry training lebih baik dibandingkan dengan model pembelajaran konvensional pada materi pokok besaran dan satuan.

\section{HASIL DAN PEMBAHASAN}

Penelitian yang dilakukan di SMA N 7 Medan populasi berasal dari kelas $\mathrm{X}$ yang terdiri dari lima kelas. Dari populasi tersebut di ambil dua kelas sebagai sampel. Untuk itu diperlukan analisis terhadap hasil belajar fisika sebelum diberikan 
perlakuan. Dari tujuh kelas tersebut, dengan cara cluster rondom sampling kelas X IPA 5 terpilih sebagai kelas eksperimen dan kelas XI IPA 1 sebagai kelas kontrol.

Sebelum kedua kelas diberikan perlakuan yang berbeda kedua kelas terlebih dahulu diberikan pretes untuk melihat kemmpuan awal siswa dan berdasarkan hasil preters yang diperoleh, nilai rata-rata pretes kelas eksperimen adalah 34,33 dengan standar deviasi 13,47 dan nilai pretes kelas kontrol 35,50 dengan standar deviasi 12,93. Selanjutnya kelas eksperimen diberi perlakuan, masing-masing kelas diberi postes. Data yang terkumpul kemudian di analisis untuk mengetahui apakah ada perbedaan akibat perlakuan pembelajaran yang diberikan.

Berdasarkan 40 responden pada kelas ekdperimen di dapat data bahwa nilai rata-rata postes sebesar 70,50 dengan standar deviasi 13,47 dan nilai rata-rata postes kelas kontrol sebesar 61,50 dengan standar deviasi 12,56. Hasil ini menunjukkan adanya perbedaan antara nilai postes kelas eksperimen yang menggunakan modelpembelajaran inquiry training dan pada kelas kontrol yang menggunakan pembelajaaran konvensional. Adanya perbedaan hasil belajar tersebut disebabkan oleh kelebihan model inquiry training tersebut yang mengaktifkan peserta didik,mengembangkan kemampuan berpikir kritis dan kreatif siswa (Harahap F, 2012), dan juga menurut Salaga (2003) bahwa pertanyaan adalah pembangkit motivasi yang dapat mnerangsang peserta didik untuk berpikir. Dari distribusi nilai pretes, postes kelas ekperimen dan kelas kontrol tersebut dibuat histogram yang dapat dilihat pada Gambar 1.

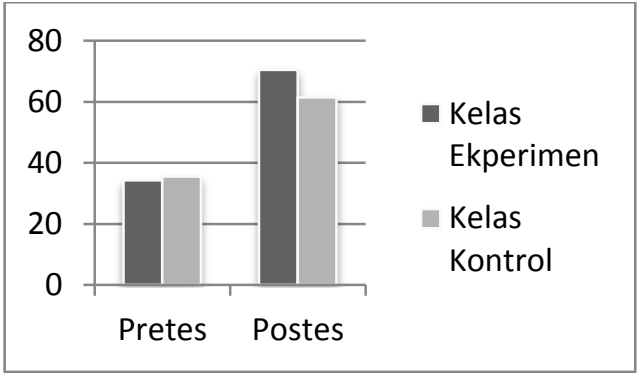

Gambar 1. Data pretes dan postes

Berdasarkan hasil uji normalitas dengan menggunakan uji Liliefors untuk kedua kelas sampel diperoleh bahwa nilai pretes dan postes berdistribusi normal seperti ditunjukkan pada Tabel 2.

Tabel 2. Hasil Uji Normalitas Pretes kedua kelas.

\begin{tabular}{|l|l|l|l|}
\hline \multirow{2}{*}{ Kelas } & \multicolumn{2}{|c|}{ Pretes } & \multirow{2}{*}{ Kesimpulan } \\
\cline { 2 - 3 } & $\mathrm{L}_{\text {hitung }}$ & $\mathrm{L}_{\text {tabel }}$ & \\
\hline Ekperimen & 0,1132 & 0,0969 & \multirow{2}{*}{ Normal } \\
\hline Kontrol & 0,1018 & 0,0974 & \\
& \multicolumn{2}{|c|}{ Postes } & \multirow{2}{*}{} \\
\cline { 2 - 3 } & L $_{\text {hitung }}$ & $\mathrm{L}_{\text {tabel }}$ & \\
\hline Ekperimen & 0,1368 & 0,1476 & \multirow{2}{*}{ Normal } \\
\hline Kontrol & 0,1415 & 0,1519 & \\
\hline
\end{tabular}

Pengujian homogenitas data pretes pada kelas kontrol dilakukan dengan uji $t$ dua pihak untuk mengetahui apakah keklompok sampel berasal dari populasi yang homogen atau tidak. Hasil uji homogenitas data yang diperoleh ditunjukkan pada Tabel 3.

\section{Tabel 3. Hasil Uji Homogenitas Kelas Ekperimen dan Kelas Kontrol.}

\begin{tabular}{|l|l|l|l|}
\hline Sampel & $\mathrm{t}_{\text {hitung }}$ & $\mathrm{t}_{\text {tabel }}$ & Kesimpilan \\
\hline Pretes & $-0,04$ & 1,99 & Homogen \\
\hline
\end{tabular}

Berdasarkan Tabel 3 tersebut dapat disimpulkan bahwa kemampuan awal siswa sama atau homogen.

Hasil uji hipotesis untuk pretes menggunakan uji t pada taraf signifikan $\alpha=0,05$. Hasil uji 
hipotesis terhadap hasilpostes dapat dilihat pada Tabel 4 .

Tabel 4. Perhitungan Uji Hipotesis Pada Kelas Ekperimen dan Kelas Kontrol.

\begin{tabular}{|l|l|l|l|}
\hline Sampel & $\mathrm{t}_{\text {hitung }}$ & $\mathrm{t}_{\text {tabel }}$ & Kesimpulan \\
\hline Postes & 6,544 & 1,668 & $\begin{array}{l}\text { Ada } \\
\text { perbedaan }\end{array}$ \\
\hline
\end{tabular}

Berdasarkan Tabel 4 dapat disimpulakan bahwa ada pengaruh model pembelajaran inquiry training terhadap hasil belajar siswa.

Aktivitas siswa selama proses pembelajaran juga diamati. Aspek aktivitas yang dinilai antara lain : mengerjakan tuga kelompok yang diberikan, mengajukan pertanyaan, memberikan tanggapan terhadap jawaban orang lain dan mencatat hasil diskusi. Aktivitas dinilai berdasarkan urutan aktivitas terendah-tertinggi, urutan pretes terendah-tertinggi berdasarkan kelompok.

Rata-rata keberhasilan per indikator dapat dilihat pada Tabel 5.

\section{Tabel 5. Presentase Penilaian} Indikator.

\begin{tabular}{|c|l|c|}
\hline No & Indikator Penilaian & $\begin{array}{c}\text { Presentase } \\
(\%)\end{array}$ \\
\hline 1 & Merumuskan masalah & 12,5 \\
\hline 2 & $\begin{array}{l}\text { Mengumpulkan data- } \\
\text { verifikasi }\end{array}$ & 10,5 \\
\hline 3 & $\begin{array}{l}\text { Menganalisis data } \\
\text { percobaan }\end{array}$ & 25 \\
\hline 4 & $\begin{array}{l}\text { Menganalisis data } \\
\text { percobaan }\end{array}$ & 37,5 \\
\hline 5 & $\begin{array}{l}\text { Merumuskan } \\
\text { kesimpulan }\end{array}$ & 35,5 \\
\hline
\end{tabular}

Berdasarkan Tabel 5 dapat dilihat bahwa hasil rata-rata penilaian perindikator masih jauh dari nilai rata-rata aktifitas. Indikator yang diharapkan dapat mendukung model pembelajaran ini tapi justryu presentasenya kecil seperti mengumpulkan data verifikasi dan merumuskan masalah. Dalam hal ini peneliti masih kurang bisa dalam menguasai kelas. Semua komponen belum berjalan lancar dan belum sempurna.

Keterlibatan siswa dalam bentuk sikap, pikiran, perhatian, dan aktifitas dalam kegiatan pembelajaran guna menunjang keberhasilan proses belajar mengajar dan memperoleh manfaat dari kegiatan tersebut masih perlu untuk lebih diperhatikan. Penerapan model inquiry training yang telah dilakukan oleh penulis belum mendapatkan hasil yang optimal karena pada pembelajaran masih ada beberapa kendala yang dihadapi oleh penulis. Nilai aktifitas siswa tidak secara keseluruhan aktifitas belajar dalam siswa adalah 52,78 termasuk dalam kriteria cukup aktif sejalan dengan kriteria kemempuan siswa juga dikrateriakan baik yaitu 72,91 tetapi diliohat dari hasil peristiwa hanya sebagian siswa dengan kriteria cukup aktif yang mampu meningkatkan hasil belajarnya menjadi baik. Hal ini dapat terjadi karena kelemahan yang terdapat dari penelitian.

Penggunaan model inquiry training dapat meningkatkan hasil belajar siswa, tetapi selama pembelajaran masih ada kendala yang dihadapi peneliti yaitu, ketika memberikan contoh pertanyaan yang cocok kepada siswa saat proses pembelajaran berlangsung.Hasil penilaian aktivitas belum dapat memberikan gambran meningkatkan hasil belajar seperti yang diharapkan, dalam hal ini kelemahan yang terjadi dapat disebabkan oleh penguasaan kelas yang belum maksimal dan juga penjelasan peneliti yang kurang memadai kepada observer.

KESIMPULAN DAN SARAN 


\section{Kesimpulan}

Berdasarkan hasil analisis
data yang dilakukan, dapat
disimpulkan bahwa hasil belajar
siswa dengan menggunakan
modelpembelajaran inquiry training
pada materi pokok besaran dan
satuan memberikan nilai rata-rata
dengan kategori baik dan cukup
aktif. Hasil belajar siswa dengan
menggunakan model pembelajaran
konvensional pada materi pokok
besaran dan satuan memberikan nilai
rata-rata dengan kategori cukup. Ada
pengaruh yang signifikan antara hasil
bnelajar siswa dengan model
pembelajaran inquiry training dean
pembelajaran konvensional pada
materi pokok besaran dan satuan di
kelas X.

Saran

Berdasarkan hasil dan kesimpulan dalampenelitian ini, makapeneliti mempunyai beberapa saran, yaitu :

1. Masih terdapat kelemahan dalam penyusunan soal berdasarkan taksonomi bloom, untuk peneliti selanjutnya sebaiknya mampu menyusun soal lebih baik lagi.

2. Untukpeneliti selanjutnya yang ingin menggunakan model pembelajaran inquiry training, supaya menginformasikan dengan tegas kepada siswa pada saat kegiatan membuat pertanyaan untuk merumuskan masalah agar membuat pertanyaan mengenai hal-hal yang kurang dipahami dan bukan untuk menguji kelompok lain.

3. Jika ditinjau dari pembahasan penelitian, hasil belajar yang mengalami peningkatan dan berpengaruh tetapi bukan karena aktivitas. Untuk peneliti selanjutnya hendaknya lebih memperhatikan deskriptordeskriptor pada penilaian aktivitas dan menggunakannya lebih baik lagi.

\section{DAFTAR PUSTAKA}

Harahap, F., (2012), Pengaruh Model Pembelajaran Inquiry Training Terhadap Hasil Belajar Siswa Pada Materi Pokok Suhu Dan Pengukuran Kelas VII Semester I Mts N 2 Medan T.P 2012/2013. Medan: FMIPA UNIMED

Joyce, et all., (2009) Model-Model

Pembelajaran, Edisi

Kedelapan. Yogyakarta : Pustaka Belajar

Sudjana, N., (2005), Metode Statistik, Bandung: Tarsito 